Linha D'Água (Online), São Paulo, v. 33, n. 2, p. 19-38, maio-ago. 2020

\title{
ENSINAR O DEBATE REGRADO SOBRE AS (DES)IGUALDADES ENTRE OS SEXOS NO PRIMÁRIO: EVOLUÇÃO DA DISTRIBUIÇÃO DA FALA ENTRE OS(AS) PARTICIPANTES
}

\author{
TEACHING THE CONTROLLED DEBATE ABOUT THE \\ (IN)EQUALITIES BETWEEN SEXES IN ELEMENTARY \\ SCHOOL: THE EVOLUTION OF THE SPEECH PROCESS \\ DISTRIBUTION AMONG PARTICIPANTS
}

\author{
Anthony Coppola* \\ Université de Genève, Genebra, Suíça \\ Foaquim Dolz** \\ Université de Genève, Genebra, Suíça
}

\begin{abstract}
Resumo: Neste artigo, buscamos apresentar os resultados da pesquisa realizada pelo grupo GRAFE (Grupo de Pesquisa para a Análise do Francês Ensinado), por meio do dispositivo Atelier Filé, implementado em três turmas de uma escola primária do Cantão de Vaud, na Suíça, com alunos com idade entre 8 e 10 anos. 0 objetivo da pesquisa era o de compreender como intervençōes didáticas espećficas e reiteradas para 0 ensino do gênero debate regrado permitem, a mesmo tempo, promover o desenvolvimento das capacidades argumentativas dos alunos em francês e influenciar a adesão dos alunos ao sistema de gênero, temática central escolhida para discussão nos diferentes debates regrados propostos pelo dispositivo. Dessa forma, os pesquisadores visavam investigar se 0 dispositivo era eficaz como procedimento para uma educação cidadã, de modo a formar cidadãos conscientes dos efeitos sociais da desigualdade de gêneros e linguisticamente atuantes na busca de maior igualdade no sistema de gêneros.
\end{abstract}

Palavras-chave: argumentação oral; debate regrado; sistema de gênero.

Abstract: This article presents the results of a research carried out by the GRAFE group (Research Group for the Analysis of French Teaching), through the use of a device called Atelier Filé, implemented in three classes of an elementary school in the Canton of Vaud, Switzerland, with students aged between 8 and 10. The research aimed at understanding how specific and repeated didactic interventions for the teaching of gender in a controlled debate allow, at the same time, to promote the development of students' argumentative abilities in French, and to influence students' adherence to the gender system, central theme chosen for discussion in different controlled debates suggested by the device. Thus, the researchers aimed at investigating whether the device was effective

* Doutorando da Université de Genève - UNIGE, Genebra, Suíça; GRAFE; https://orcid.org/0000-0003-2380-3191; anthony.coppola@unige.ch * * Professor Doutor da Université de Genève - UNIGE, Genebra, Suíça; GRAFE; htrps://orcid.org/0000-0003-1488-0240; joaquim.dolz-mestre@unige.ch

http://dx.doi.org/10.11606/issn.2236-4242.v33i2p19-38 
Linha D’Água (Online), São Paulo, v. 33, n. 2, p. 19-38, maio-ago. 2020

as a procedure for citizen education, in order to form citizens aware of the social effects of gender inequality and linguistically active in the search for greater equality in the gender system.

Keywords: Oral Argumentation; Regulated Debate; Gender System.

Como fator socializante essencial, a escola é construída nos princípios de igualdade e de emancipação para todas e todos ${ }^{1}$. No entanto, embora ela se proclame igualitária, sabemos, há muito tempo, que as desigualdades sociais (de classe, de gênero e de raça) vivem e se (re)produzem nessa instituição (BOURDIEU, PASSERON, 1970; COLLET, 2017). Assim, a diversidade, contrariamente ao que se pensa, não basta para garantir uma educação igualitária entre meninas e meninos (COLLET, DAYER, 2014). De fato, as diferenças mínimas de tratamento e de percepção estereotipadas entre elas e eles no cotidiano acabam por desencadear grandes desigualdades (ROWE, 2008), o que vai, entre outros, coagir as escolhas de orientação e de profissões dos indivíduos em função de seus sexos (VOUILLOT, 2007). Essas desigualdades advêm do sistema de gênero entendido como um conjunto de normas produzidas pelos vínculos sociais que definem, hierarquizam e legitimam o feminino e o masculino (COLLET, 2017). Além de dificultar os percursos profissionais dos indivíduos, no quadro escolar, o gênero pode impactar a saúde psíquica e física dos(as) aprendizes (baixa autoestima, sentimento de vergonha, ansiedade, depressão e suicídio) (DAYER, 2017), assim como suas modalidades de aprendizagem (evasão escolar, abandono escolar, comprometimento do clima em sala de aula) (CHAMBERLAND, 2010).

A escola deve se conscientizar de seu papel na (re)produção do gênero, onipresente na sociedade, e ir além, caso contrário, ela se tornará cúmplice das formas de rejeição que ela desencadeia. Nessa perspectiva, as pedagogias de conscientização ${ }^{2}$ provenientes originariamente da pedagogia dos oprimidos de Freire (1974) são politicamente necessárias para a emancipação. Dentre elas, a

1 Tradução de Aline Hitomi Sumiya (USP), Mariane Damasceno (USP), Suélen Maria Rocha (UEL). Revisado por Eliane Gouvêa Lousada (USP).

2 Tais como a pedagogia crítica da norma, antirracista, queer, intercultural, ecopedagogia ou feministas.

COPPOLA, A., DOLZ, J. Ensinar o debate regrado sobre as (des)igualdades entre os sexos no primário: Evolução da distribuição da fala entre os(as) participantes 
Linha D'Água (Online), São Paulo, v. 33, n. 2, p. 19-38, maio-ago. 2020

pedagogia da igualdade (COLLET, 2017) questiona as dimensões materiais dos processos de dominação, com a finalidade de desenvolver nos(as) alunos(as) um saber crítico. A abertura do diálogo, sem tabu, com os(as) alunos(as), constitui uma ferramenta fundamental para permitir esse desenvolvimento. Consequentemente, o ensino do debate é conveniente, uma vez que ele dá acesso ao pensamento do outro, levando os(as) alunos(as) a desenvolver seu espírito cívico e crítico, assim como assumir uma posição respeitando as dos outros (DOLZ, SCHNEUWLY, 1988/2016). Além disso, a confrontação argumentada de ideias presencialmente e dentro de um coletivo de discussão representa uma ferramenta útil e poderosa, por compreender o mundo ao nosso redor, lutando contra as desigualdades sociais (GARCIA-DEBANC, 2016). É com a finalidade de uma educação para a cidadania que criamos um dispositivo de ensino/aprendizagem, o Atelier Filể, a fim de fazer com que os(as) alunos(as) debatam sobre questões de (des)igualdade entre os sexos e as sexualidades.

Com esta pesquisa, pretendemos compreender os efeitos de intervenção específicos, visando o desenvolvimento das competências de debate dos alunos e ver como elas influenciam sua adesão no sistema de gênero. Em uma primeira publicação, já destacamos que o fato de formar os(as) alunos(as) sobre conteúdo discriminatório permite que eles e elas evoluam para a uma maior independência do sistema de gênero (COPPOLA, COLOGNESI, COLLET, no prelo). Neste artigo, focaremos nosso olhar na evolução da distribuição da fala entre os(as) diferentes participantes para identificar se os seus comportamentos nos atos evoluem para uma maior igualdade em função dos ensinamentos recebidos.

Antes de apresentar o dispositivo do Atelier Filé, esclareceremos, primeiramente, como as tomadas de turno entre meninas e meninos é desigual em aulas. Em seguida, detalharemos o gênero textual debate regrado, considerado como um meio privilegiado para exercitar as tomadas de turno em sala de aula sobre questões de cidadania.

3 Nota das tradutoras: Este dispositivo é desenvolvido por GRAFE (Groupe de Recherche pour l'Analyse du Français Enseigné). Mais informações em https://www.unige.ch/fapse/grafe/

COPPOLA, A., DOLZ, J. Ensinar o debate regrado sobre as (des)igualdades entre os sexos no primário: Evolução da distribuição da fala entre os(as) participantes 
Linha D'Água (Online), São Paulo, v. 33, n. 2, p. 19-38, maio-ago. 2020

\section{0 efeito do sistema de gêneros nas tomadas de turno desiguais na escola}

Desde os anos de 1980, as ciências da educação mostraram que os(as) professores(as), independentemente de seu gênero, privilegiam mais os meninos do que as meninas nas interações em sala de aula (COLLET, 2017; MOSCONI, 2017). No primário, quantitativamente, essas interações tendem a se equilibrar, ainda que os meninos obtenham uma vantagem (JARLÉGAN; TAZOUTI; FLIELLER, 2011). No entanto, no secundário obrigatório, assim como no pós-obrigatório, por questões de competição e visibilidade, as trocas entre os(as) professores(as) e meninos são duas vezes mais frequentes do que as trocas entre os(as) professores(as) e as meninas, o que resultou na regra dos dois terços/um terço (BROPHY; GOOD, 1986). Os(as) professores(as), em geral, não têm consciência dessas diferenças de tratamento co-construídas com os(as) alunos(as), pois, se elas e eles tentam restabelecer interações mais equilibradas, os meninos reclamam de serem negligenciados e os(as) professores(as) também têm a impressão de desfavorecê-los (MOSCONI, 2001). Essas representações causadas pelo (sistema de) gênero reforçam as desigualdades e incentivam as meninas a ficarem para trás, o que pode causar mais dificuldades no mundo adulto, que exige que saibamos nos vender e nos exprimir em sociedade (COLLET; MOSCONI, 2010). Portanto, para questões de igualdade, é necessário sensibilizar os(as) professores(as) sobre essa problemática. Assim, o ensino do oral pode desempenhar um papel impulsionador para que cada aluno(a), menina ou menino, exerça o turno de fala em público.

\section{0 ensino do debate regrado no oral}

Desde os anos de 1990, fazer os(as) alunos(as) debaterem em sala de aula, qualquer que seja a disciplina escolar, tem sido significativo na escola com o objetivo de saber se posicionar e construir valores. Essa prática permite inverter o contrato didático habitual, visto que são os(as) alunos(as), e não mais o(a) professor(a), que tomam a palavra e se afirmam. Dentre a grande variedade de formas de debate, o debate regrado pode ser definido como uma discussão que ocorre em público entre

COPPOLA, A., DOLZ, J. Ensinar o debate regrado sobre as (des)igualdades entre os sexos no primário: Evolução da distribuição da fala entre os(as) participantes 
Linha D’Água (Online), São Paulo, v. 33, n. 2, p. 19-38, maio-ago. 2020

vários parceiros(as), organizado e dirigido por um moderador ou uma moderadora a partir de uma pergunta controversa, com vistas à mudança de opinião ou de atitudes do público (DOLZ, NOVERRAZ; SCHNEUWLY, 2001). Constantemente utilizado nas sociedades democráticas como forma de tornar visíveis as opiniões políticas, sua presença é relativamente frequente nas mídias. (DOLZ; SCHNEUWLY, 1998/2016). O ensino do debate é útil para desenvolver o espírito crítico e cívico dos(as) alunos(as) e para evitar os efeitos da manipulação onipresentes, por meio de informações densas e não hierarquizadas em nossa sociedade. Do ponto de vista linguístico, diversas aprendizagens podem ser realizadas: levar em consideração o discurso do outro pela reformulação, o ato de questionar, as marcas de refutação, a modalização, o apoio argumentativo. Sobre o plano individual, essa forma de debate dá possibilidade de se posicionar e de construir sua identidade.

Nessa produção oral organizada e poligerida, os debatedores e debatedoras devem defender uma opinião desenvolvendo-a com argumentos para convencer o público. Quanto ao moderador ou à moderadora, ela ou ele deve assumir mais funções. Além de se encarregar de motivar o público a se interessar pelo debate, recorrendo a uma prosódia cativante, ela/ele se ocupa de realizar a abertura, colocando a pergunta de controvérsia, apresentando o contexto, assim como os(as) participantes do debate. Durante a fase de argumentação, ela/ele deve ficar neutro(a), distribuir a fala aos diferentes intervenientes; fazer perguntas para sustentar as opiniões de cada um(a); perguntar para esclarecer ou pedir mais precisões, caso necessário; reformular as palavras dos participantes, a fim de fazer com que os(as) outros(as) reajam; ou mesmo reorientar as discussões em torno da questão controversa. Por fim, como forma de encerramento, ela/ele é levado(a) a propor um breve enunciado conclusivo, agradecendo ao público e aos(às) convidados(as) por terem participado do debate, bem como apresentar, possivelmente, o tema do debate seguinte.

Sob diferentes perspectivas, preconizamos um ensino autônomo do oral, ainda que se trate de uma prática minoritária nas aulas (DUPONT, 2016; SÉNÉCHAL, 2016). Contudo, ensinar o oral enquanto objeto de ensino/aprendizagem justifica-se tanto nos planos individual, social, das aprendizagens escolares, assim como para objetivos de justiça social (COPPOLA, COLOGNESI, COLLET, no prelo). Portanto, é nesse contexto escasso em ensino-aprendizagem específico do 
Linha D'Água (Online), São Paulo, v. 33, n. 2, p. 19-38, maio-ago. 2020

oral que escolhemos experimentar o Atelier Filé, cujo nome é uma homenagem aos ateliers de filosofia ${ }^{4}$, um dispositivo que visa ensinar o debate regrado, mantendo as principais linhas de força de dois dispositivos existentes, a saber, as Sequências Didáticas (DOLZ; NOVERRAZ; SCHNEUWLY, 2001) e o Dispositivo Itinerário (COLOGNESI; DESCHEPPER, 2019).

Uma Sequência Didática (DOLZ; NOVERRAZ; SCHNEUWLY, 2001) visa ensinar as línguas por meio de verdadeiras produções orais e escritas a partir de gêneros de texto (o conto, a receita de cozinha, a exposição oral ${ }^{5}$ etc.). A fim de dar sentido e motivar os alunos nas aprendizagens, em uma primeira etapa de apresentação da situação, as produções escritas e orais são trabalhadas em um projeto comunicativo (escrever uma coletânea de contos para as outras salas, apresentar exposições em uma confraternização com os pais, elaborar sequências de vídeo ou radiofônicas de receitas de cozinha etc.). Em seguida, uma produção inicial permite ao/à professor(a) identificar os pontos fortes e os desafios dos alunos, com o objetivo de superá-los nos módulos de aprendizagem. Uma produção final, no fim da sequência, dá a possibilidade de avaliar a progressão dos alunos e a apropriação do gênero textual estudado. Desse dispositivo, mantemos o trabalho com a produção inicial e final.

O Dispositivo Itinerário (COLOGNESI, DESCHEPPER, 2019) propõe um desenvolvimento das Sequências Didáticas permitindo aos alunos evoluir suas capacidades de linguagem no oral e no escrito, por meio de variadas práticas do gênero textual ao longo da sequência. Três formas são utilizadas para o desenvolvimento das capacidades em comunicação oral ou escrita dos alunos: intervenções ${ }^{6}$ organi- $^{-}$ zadas pelo(a) professor(a) em função das dificuldades identificadas; releituras ou reescuta colaborativa entre alunos(as); mediações metacognitivas contínuas para

4 Originalmente, havíamos pensado em propor ateliers de filosofia para que os(as) alunos(as) discutissem sobre questões ligadas ao sistema de gênero. Percebemos, no entanto, que os(as) alunos(as), com prudência, evitavam de se afastar das normas de gênero, o que impedia o surgimento de conflitos sociocognitivos. Foi graças a essa experiência, cuja marca se cristalizou na primeira parte do nome do dispositivo, que pensamos na prática do debate regrado.

5 Nota das tradutoras: No Brasil, Exposé oral também é conhecido como Seminário escolar. Optamos por manter exposição oral em coerência com a tradução do livro Gêneros orais e escritos na escola (SCHNEUWLY, DOLZ, 2013).

6 Nota das tradutoras: no texto original, des $\backslash$.

COPPOLA, A., DOLZ, J. Ensinar o debate regrado sobre as (des)igualdades entre os sexos no primário: Evolução da distribuição da fala entre os(as) participantes 
Linha D'Água (Online), São Paulo, v. 33, n. 2, p. 19-38, maio-ago. 2020

que os alunos se conscientizem dos seus comportamentos linguageiros por meio de atividades que permitem que eles se questionem e explicitem seus atos, suas estratégias, bem como seus progressos (COLOGNESI, DOLZ, 2017). Desse segundo dispositivo, guardaremos a ideia das múltiplas possibilidades de reoralização, uma vez que os alunos são levados a debater semanalmente. Além disso, recorreremos também às mediações metacognitivas centradas diretamente em torno dos debates regrados. Por fim, as intervenções que propomos são organizadas pelo(a) professor(a), procurando favorecer a colaboração entre os(as) alunos(as) nas atividades de aprendizagem propostas.

Descreveremos, agora, o trabalho com esse dispositivo, antes de apresentar os nossos percursos metodológicos, visando mensurar a evolução das tomadas de turno entre os(as) alunos(as) em cada uma das modalidades, que nos permitirá identificar qual o impacto do Atelier Filé na evolução da distribuição dos turnos de fala entre os diferentes participantes.

\section{Metodologia}

\section{1 Implementação do Atelier Filé}

O Atelier Filé é um dispositivo organizado em sequências de atividades de aprendizagem que visa desenvolver a fala e o pensamento crítico, propondo que os(as) alunos(as) debatam periodicamente sobre questões relacionadas ao sistema de gênero. Ele tem a particularidade de oferecer, entre os sucessivos turnos de fala em público dos alunos, módulos de aprendizagem sobre as dimensões do debate a melhorar e a desenvolver. Assim, como ilustra o esquema da figura 1, seguido de uma apresentação da situação, os(as) alunos(as), semanalmente, tiveram a oportunidade de praticar um debate regrado: uma produção inicial, três produções intermediárias e uma produção final. Essa prática regular dos debates, inspirada no Dispositivo Itinerários, originou, como a figura de estilo de métaphore fllée ${ }^{7}$, a segunda parte do nome de nosso dispositivo.

7 Nota das tradutoras: Métaphore filée se refere a uma figura de estilo constituída de variadas metáforas seguidas umas das outras sobre um mesmo tema.

COPPOLA, A., DOLZ, J. Ensinar o debate regrado sobre as (des)igualdades entre os sexos no primário: Evolução da distribuição da fala entre os(as) participantes 
O desenvolvimento de um debate regrado, no quadro do Atelier Filé, é sempre organizado da mesma forma. $\mathrm{O}(\mathrm{A})$ professor(a) faz uma pergunta controversa sobre uma questão ligada ao sistema de gênero. Os (As) alunos(as) inventam e anotam individualmente os argumentos a favor e contra em uma folha. Em seguida, elas e eles formam grupos para compartilhar seus argumentos em função do papel fictício que cada membro do grupo desempenhará, a saber: Senhora Joba, coordenadora de uma associação pela igualdade entre as mulheres e os homens, e Senhor Kafo, cabeleireiro, como debatedores sustentando uma posição igualitária; Senhor Toto, treinador de futebol, e senhora Lala, responsável de uma loja de brinquedos, como debatedores defendendo uma posição desigualitária. Em grupo de cinco - (um debatedor e uma debatedora igualitário(a), um moderador ou uma moderadora, assim como um debatedor e uma debatedora desigualitário(a) - os(as) alunos(as) produzem um debate regrado na frente dos(as) outros(as) alunos(as) que desempenham o papel do público a ser convencido. Questões metacognitivas são feitas aos(às) participantes antes e após cada debate. Por fim, entre os debates regrados, em função das dificuldades, atividades de aprendizagem em forma colaborativa são programadas pelos(as) professores(as) para permitir que elas/eles melhorem sua produção oral.

Fig. 1: Esquema simplificado do Atelier Filé

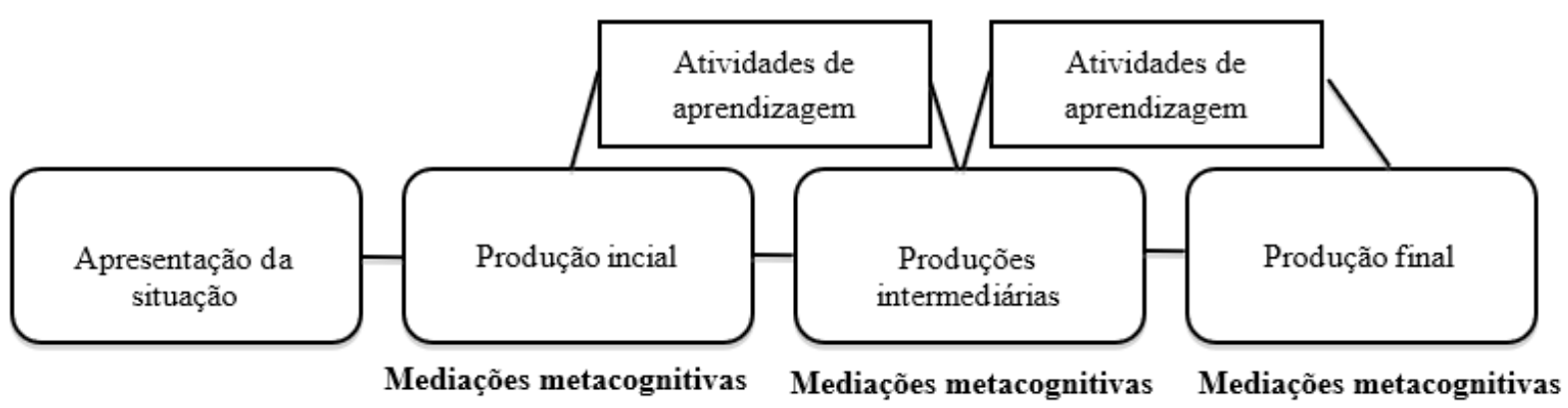

Para avaliar a pertinência das escolhas de ensinamentos específicos sobre o oral e/ou sobre os conceitos discriminatórios e identificar como esses ensinamentos são reinvestidos pelos(as) alunos(as) nos debates regrados, testamos uma modalidade diferente em três classes da escola primária do Cantão de Vaud na Suíça de alunos(as) de 8-10 anos. No total, 57 alunos(as) participaram deste estudo: 20 alunos(as) na 
Linha D'Água (Online), São Paulo, v. 33, n. 2, p. 19-38, maio-ago. 2020

turma 1 ( 9 meninas, 11 meninos); 20 alunos(as) na turma 2 ( 8 meninas, 12 meninos) e 17 alunas(os) na turma 3 ( 9 meninas, 8 meninos). Essas turmas participaram deste projeto durante cinco semanas, do início de novembro até meados de dezembro de 2018. Como indica a figura 2 , a primeira turma (modalidade 1) recebeu um ensino específico sobre os conceitos ligados às discriminações e aos princípios do (sistema) de gênero. A professora da segunda turma (modalidade 2) propôs intervenções sobre o oral e sobre o gênero. Por fim, as intervenções foram unicamente sobre o oral na terceira turma (modalidade 3). A comparação das três modalidades nos permitirá, seguindo as análises, identificar o modelo mais pertinente.

Fig. 2: Desenvolvimento das três modalidades do Atelier Filé

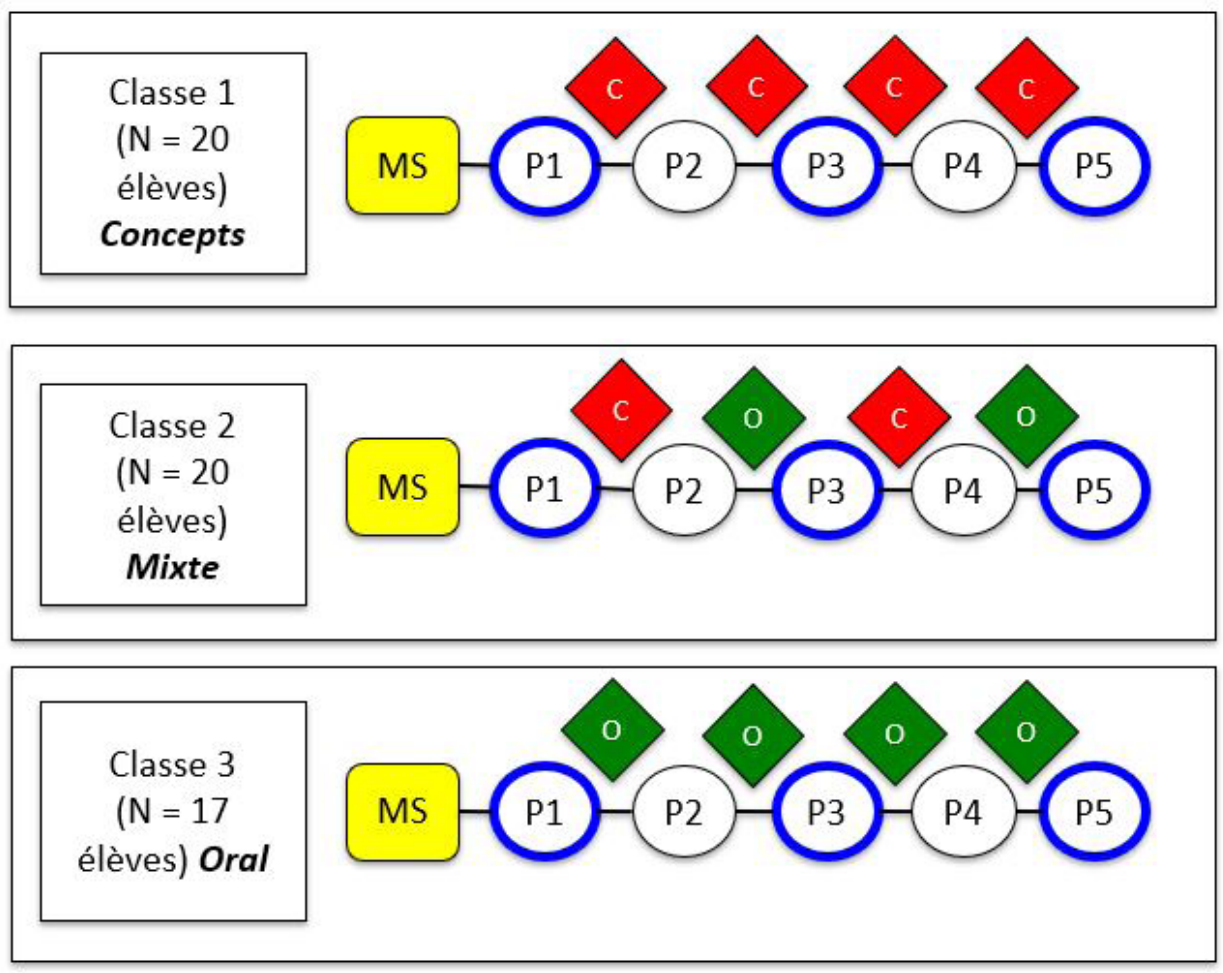

MS: apresentação da situação; P: produção oral (debate regrado); O: intervenção no oral;

C: intervenção nos conceitos

Na modalidade conceitos, propomos um ensino específico sobre os conteúdos dos debates, a saber, os mecanismos discriminatórios. Os alunos aprenderam a compreender e a utilizar uma série de noções associadas à compreensão do sistema de gênero (norma, categorização, estereótipo, preconceito, discriminação, racismo,

COPPOLA, A., DOLZ, J. Ensinar o debate regrado sobre as (des)igualdades entre os sexos no primário: Evolução da distribuição da fala entre os(as) participantes 
sexismo, homofobia etc.), com a finalidade de questionar as relações de poder na nossa sociedade e sua organização sexual (MARRO, 2012).

$\mathrm{Na}$ modalidade oral, os(as) alunos(as) aprenderam a desempenhar o papel de moderador ou moderadora. Elas e eles aprenderam também a sustentar uma opinião com argumentos (sobre diversas temáticas distantes das de gênero). Estratégias para refutar ou sustentar as opiniões $\operatorname{dos}($ as) outros(as) debatedores(as) foram ensinadas, valorizando as expressões de responsabilidade enunciativa variadas ( $n a$ minha opinião, eu não compartilho da sua opinião, eu concordo com você, etc.). Por fim, os(as) alunos(as) dessa modalidade tiveram a oportunidade de encenar para progredir na forma de interpretar um personagem (voz, postura, escolha dos argumentos em função de seu estatuto).

Enfim, na modalidade mista, a cada semana, a professora alternava atividades de aprendizagem sobre os conteúdos discriminatórios e sobre o oral. O quadro, em seguida, apresenta a ordem dos ensinamentos propostos em cada uma das modalidades com a escolha das perguntas controversas selecionadas conjuntamente com os(as) professores(as).

Tabela 1: Organização das atividades de aprendizagem no Atelier Filé

\begin{tabular}{|c|c|c|c|}
\hline & Conceitos & Misto & Oral \\
\hline Debate 1 & \multicolumn{3}{|c|}{ "Deve-se separar os meninos e as meninas na ginástica na escola?" } \\
\hline Atividade 1 & $\begin{array}{l}\text { Sistema Discriminatório } \\
(1 / 2)\end{array}$ & Sistema Discriminatório & $\begin{array}{c}\text { Funções do } \\
\text { moderador e da } \\
\text { moderadora }\end{array}$ \\
\hline Debate 2 & \multicolumn{3}{|c|}{ "Os pais devem cuidar das crianças tanto quanto as mães?" } \\
\hline Atividade 2 & $\begin{array}{c}\text { Sistema Discriminatório } \\
(2 / 2) \\
\text { Sexismo }(1 / 2)\end{array}$ & $\begin{array}{l}\text { Funções do moderador e } \\
\text { da moderadora }\end{array}$ & $\begin{array}{l}\text { Funcionamento de } \\
\text { um debate regrado e } \\
\text { formulação de uma } \\
\text { opinião argumentada }\end{array}$ \\
\hline Debate 3 & \multicolumn{3}{|c|}{$\begin{array}{l}\text { "Devemos incentivar os garotos de cinco ou seis anos a brincar com bonecas } \\
\text { na escola?" }\end{array}$} \\
\hline Atividade 3 & $\begin{array}{c}\text { Sexismo }(2 / 2) \\
\text { Homofobia }(1 / 2)\end{array}$ & Sexismo & $\begin{array}{l}\text { Discutir com os } \\
\text { outros debatedores }\end{array}$ \\
\hline
\end{tabular}

[continua]

COPPOLA, A., DOLZ, J. Ensinar o debate regrado sobre as (des)igualdades entre os sexos no primário: Evolução da distribuição da fala entre os(as) participantes 
Linha D'Água (Online), São Paulo, v. 33, n. 2, p. 19-38, maio-ago. 2020

[continuação]

\begin{tabular}{|l|c|c|c|}
\cline { 2 - 4 } \multicolumn{1}{c|}{} & Conceitos & Misto & Oral \\
\hline Debate 4 & \multicolumn{2}{c|}{ "Devemos falar de homo parentalidade na escola?" } \\
\hline Atividade 4 & Homofobia (2/2) & $\begin{array}{c}\text { Discutir com os outros } \\
\text { debatedores }\end{array}$ & $\begin{array}{c}\text { Encenar, interpretar } \\
\text { um personagem }\end{array}$ \\
\hline Debate 5 & "Devemos banir as seções para meninas e para meninos nas lojas?" \\
\hline
\end{tabular}

Notemos que, em cada modalidade, somente um debate inicial (debate 1), um debate intermediário (debate 3) e um debate final (debate 5) foram filmados e transcritos para analisar a evolução das capacidades de linguagem no oral. Com o objetivo de identificar a evolução fina das capacidades de linguagem, cinco alunos por modalidade interpretaram os mesmos papéis fictícios nos três debates analisados. Após a sequência, um Focus Group foi utilizado com cada grupo, permitindo identificar as posições pessoais de cada um(a) sobre o sistema de gênero e para identificarmos as impressões dos(as) alunos(as) na prática do debate regrado.

Agora que apresentamos mais detalhes sobre o dispositivo Atelier Filé, voltar-nos-emos ao método de análise utilizado, o que nos permite observar as trocas dialogadas entre os(as) participantes nos debates regrados e avaliar a evolução da dinâmica desses(as) participantes.

\subsection{A dinâmica das trocas dialogadas como indicador de igualdade}

Em um debate regrado, as interações são complexas de identificar em razão da dinâmica,que não segue uma ordem pré-estabelecida. Contudo, na discussão poligerida que constitui o debate regrado, o moderador ou a moderadora tem como função zelar para que a fala seja distribuída de maneira igualitária entre os(as) diferentes intervenientes. Atrair nosso olhar sobre as interações verbais nos permitirá descobrir como, da produção inicial à produção final, a dinâmica das trocas dialogadas e as relações de lugar evoluem entre os debatedores e debatedoras (BRONCKART, 1997), o que nos permitirá avaliar o impacto do nosso dispositivo na dinâmica das trocas dialogadas. A fim de identificar essa dinâmica, centrar-nos-emos (1) no número de tomadas de turno de cada interveniente e (2) nos

COPPOLA, A., DOLZ, J. Ensinar o debate regrado sobre as (des)igualdades entre os sexos no primário: Evolução da distribuição da fala entre os(as) participantes 
turnos de fala, isto é, o acompanhamento da discussão, que permite identificar a ordem das intervenções entre os(as) participantes. Para identificar o número de tomadas de turno, contabilizamos o número de intervenções por participante(s) que, em seguida, transformamos em porcentagem, para facilitar a comparação entre os diferentes grupos (ver tabela 2). Para avaliar os turnos de fala, concebemos um esquema gráfico por debate seguindo o fio da discussão (ver figura 3). Cada traço designa um turno de fala. Os indicadores de igualdade que levamos em conta em nossa análise se referem, por um lado, ao papel fictício que os alunos encarnam defendendo posições igualitárias e desigualitárias e, por outro lado, ao sexo. Os indicadores quantitativos nos indicam sua frequência, enquanto a análise de excertos específicos da transcrição de nosso corpus em relação às noções abordadas permite explicitar os conteúdos desenvolvidos em torno dos turnos de fala e completa qualitativamente esse indicador de igualdade.

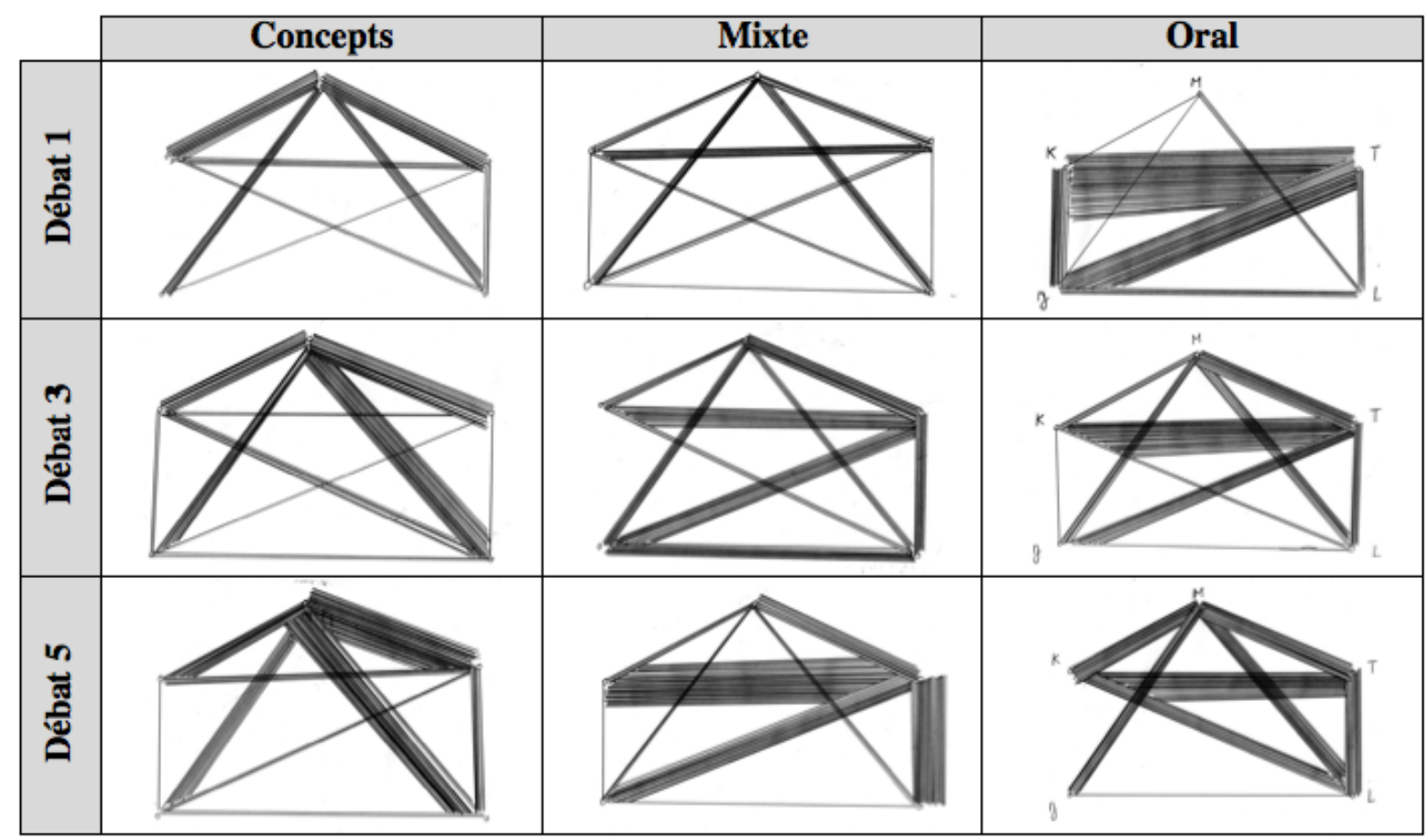

No topo dos esquemas: o moderador ou a moderadora, acima à esquerda, Kafo (debatedor igualitário), abaixo à esquerda, Joba (debatedora igualitária), acima à direita, Toto (debatedor desigualitário), abaixo à direita, Lala (debatedora desigualitária) 
Linha D'Água (Online), São Paulo, v. 33, n. 2, p. 19-38, maio-ago. 2020

Antes de analisar esses dados, é conveniente apresentar a porcentagem das tomadas de turno por cada participante durante os debates filmados (tabela 2, abaixo). A tabela reagrupa essas porcentagens segundo nossos indicadores de igualdade, a saber, o sexo e a posição a defender dos diferentes debatedores e debatedoras para os três debates gravados.

Tabela 2: Porcentagens das tomadas de turno nos três debates filmados do Atelier Filé para cada participante e em função do sexo e da posição a defender

\begin{tabular}{|c|c|c|c|c|c|c|}
\hline \multirow[b]{2}{*}{ Modalidade } & \multirow{2}{*}{$\begin{array}{l}\text { Papéis } \\
\text { fictícios }\end{array}$} & \multicolumn{3}{|c|}{ Porcentagem de tomadas de fala } & \multirow{2}{*}{$\begin{array}{c}\text { Sexo } \\
\text { D1, D3, } \\
\text { D5 }\end{array}$} & \multirow{2}{*}{$\frac{\text { Posição }}{\text { D1, D3, D5 }}$} \\
\hline & & Debate 1 & Debate 3 & Debate 5 & & \\
\hline \multirow{5}{*}{ Conceitos } & Mod & 40 & 40 & 38 & - & - \\
\hline & Joba & 8 & 10 & 9 & \multirow{2}{*}{$\begin{array}{l}\text { Meninas } \\
20,28,26 \\
\end{array}$} & \multirow{2}{*}{$\begin{array}{c}\text { Igualitários } \\
26,25,19\end{array}$} \\
\hline & Kafo & 18 & 15 & 10 & & \\
\hline & Toto & 22 & 15 & 26 & \multirow{2}{*}{$\begin{array}{l}\text { Meninos } \\
40,30,36 \\
\end{array}$} & \multirow{2}{*}{$\begin{array}{c}\text { Desigualitários } \\
34,33,43 \\
\end{array}$} \\
\hline & Lala & 12 & 18 & 17 & & \\
\hline \multirow{5}{*}{ Misto } & Mod & 28 & 20 & 9 & - & - \\
\hline & Joba & 16 & 20 & 10 & \multirow{2}{*}{$\begin{array}{l}\text { Meninas } \\
30,37,26\end{array}$} & \multirow{2}{*}{$\begin{array}{c}\text { Igualitários } \\
35,34,33 \\
\end{array}$} \\
\hline & Kafo & 19 & 14 & 23 & & \\
\hline & Toto & 22 & 30 & 42 & \multirow{2}{*}{$\begin{array}{l}\text { Meninos } \\
41,44,65\end{array}$} & \multirow{2}{*}{$\begin{array}{c}\text { Desigualitários } \\
36,47,58\end{array}$} \\
\hline & Lala & 14 & 17 & 16 & & \\
\hline \multirow{5}{*}{ Oral } & Mod & 2 & 20 & 24 & - & - \\
\hline & Joba & 24 & 13 & 9 & \multirow{2}{*}{$\begin{array}{l}\text { Meninas } \\
32,24,26\end{array}$} & \multirow{2}{*}{$\begin{array}{c}\text { Igualitários } \\
54,34,32\end{array}$} \\
\hline & Kafo & 30 & 21 & 23 & & \\
\hline & Toto & 37 & 35 & 27 & \multirow{2}{*}{$\begin{array}{l}\text { Meninos } \\
67,56,50\end{array}$} & \multirow{2}{*}{$\begin{array}{c}\text { Desigualitários } \\
45,46,44\end{array}$} \\
\hline & Lala & 8 & 11 & 17 & & \\
\hline
\end{tabular}

Mod: moderador ou moderadora, Joba: debatedora igualitária, Kafo: debatedor igualitário, Toto: debatedor desigualitário, Lala: debatedora desigualitária.

Como nós podemos observar com a figura 3, a tendência geral é de aumento das tomadas de turno. Os números falam por si. Da produção inicial à produção 
Linha D’Água (Online), São Paulo, v. 33, n. 2, p. 19-38, maio-ago. 2020

final, as tomadas de turno passam de 50 a 95 na modalidade conceitos, de 36 a 95 na modalidade mista e de 92 a 111 na modalidade oral. Qualquer que seja a modalidade, parece que quanto mais os(as) alunos(as) são levados(as) a praticar debates regrados, mais as trocas são numerosas entres os(as) diferentes participantes. Contudo, não é porque as trocas são mais numerosas que todos(as) os(as) alunos(as) se expressam mais e de maneira igualitária em função de seu sexo e de sua posição a defender.

Com relação ao critério do sexo, qualquer que seja a modalidade, os debatedores intervêm sempre mais do que as debatedoras no conjunto dos debates filmados. Por outro lado, a distância não se aprofunda da mesma maneira como podemos constatar na figura 4. $\mathrm{Na}$ modalidade conceitos, enquanto os meninos tomam duas vezes mais a fala do que as meninas na produção inicial, essa distância tende a diminuir ligeiramente, passando de uma proporção de 40/20 para uma proporção de 36/26. Na modalidade mista, os meninos monopolizam a fala, passando de uma proporção de 41/30 para uma proporção de $65 / 25$. Na modalidade oral, essa proporção permanece duplicada para o conjunto dos debates filmados, passando de uma proporção de 67/32 para uma proporção de 50/26. Segundo esses resultados, parece que formar os alunos para os conceitos discriminatórios e para o (sistema de) gênero de maneira intensiva permitiria às meninas tomar cada vez mais espaço e se distanciar da regra habitual colocada em evidência por Brody e Good (1986) dos $2 / 3$ de tomadas de turno para os meninos e $1 / 3$ para as meninas.

Fig. 4: Evolução das tomadas de turno entre meninas e meninos

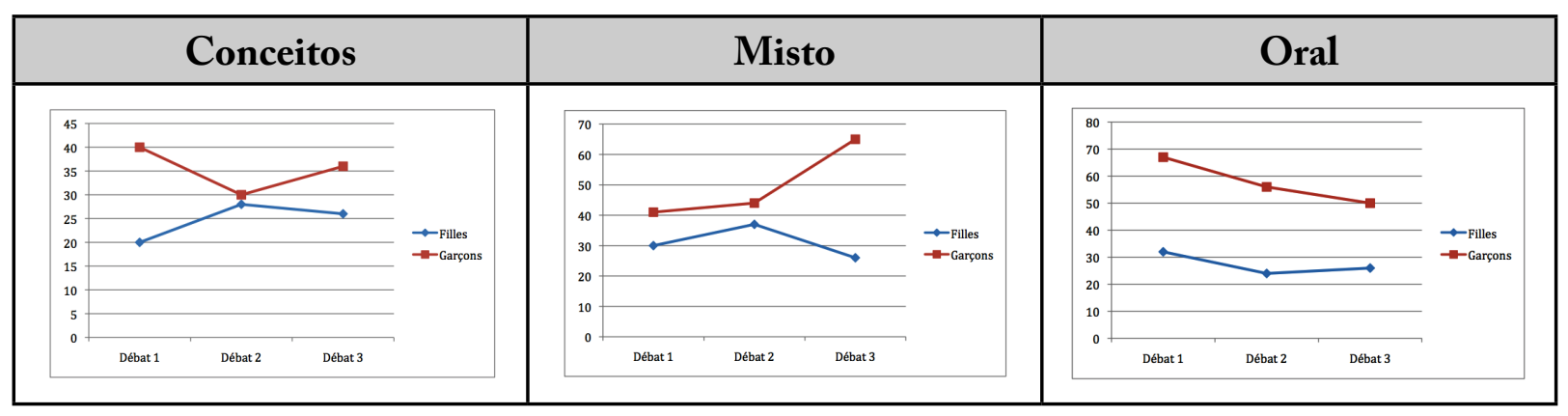

Com relação ao critério da posição desigualitária a defender, como ilustra a figura 5, com exceção da produção inicial na modalidade oral (54/45), os debatedores

COPPOLA, A., DOLZ, J. Ensinar o debate regrado sobre as (des)igualdades entre os sexos no primário: Evolução da distribuição da fala entre os(as) participantes 
e as debatedoras que sustentam uma posição desigualitária tomam mais a palavra do que aquelas e aqueles que defendem uma posição igualitária. Mais uma vez, a evolução dessa distância não é a mesma segundo a modalidade de ensino vivenciada. Enquanto na modalidade oral, a proporção está ligeiramente a favor dos defensores da desigualdade na produção final (44/32), essa distância sobre os conceitos discriminatórios é exponencial nas modalidades, tendo sido formadas para o sistema de gênero. De fato, na modalidade conceitos, a proporção de 34/26 passa para 43/19 e na modalidade mista, de uma proporção quase igualitária de 36/35 para uma proporção duplicada de 58/33. Esses resultados nos interpelam, visto que esperávamos que os(as) alunos(as) formados(as) para a igualdade privilegiassem atitudes mais igualitárias na distribuição das tomadas de turno. No entanto, é o contrário que aconteceu. Isso se deve, provavelmente ao fato de que o fato de ter tomado consciência das relações de poder na sociedade deu aos(às) alunos(as) as chaves para melhor encarnar seu papel fictício desigualitário. Por essa razão, os(as) alunos(as) formados(as) para a desigualdade apresentaram, ao longo dos debates, atitudes cada vez mais desigualitárias, cortando ou tomando a fala à força, por exemplo. Além disso, é interessante constatar que os(as) alunos(as), interpretando debatedores ou debatedoras que defendem uma posição desigualitária, apoiam-se mais uns nos outros que os defensores da igualdade, sejam eles formados ou não ao oral. As trocas mais numerosas entre os debatedores desigualitários são visíveis na figura 3. Quanto aos debatedores e debatedoras que sustentam posições igualitárias, elas e eles esperam mais que o moderador ou a moderadora lhes dê a palavra para se exprimir.

Fig. 5: Evolução das tomadas de turno entre papeis igualitários et desigualitários

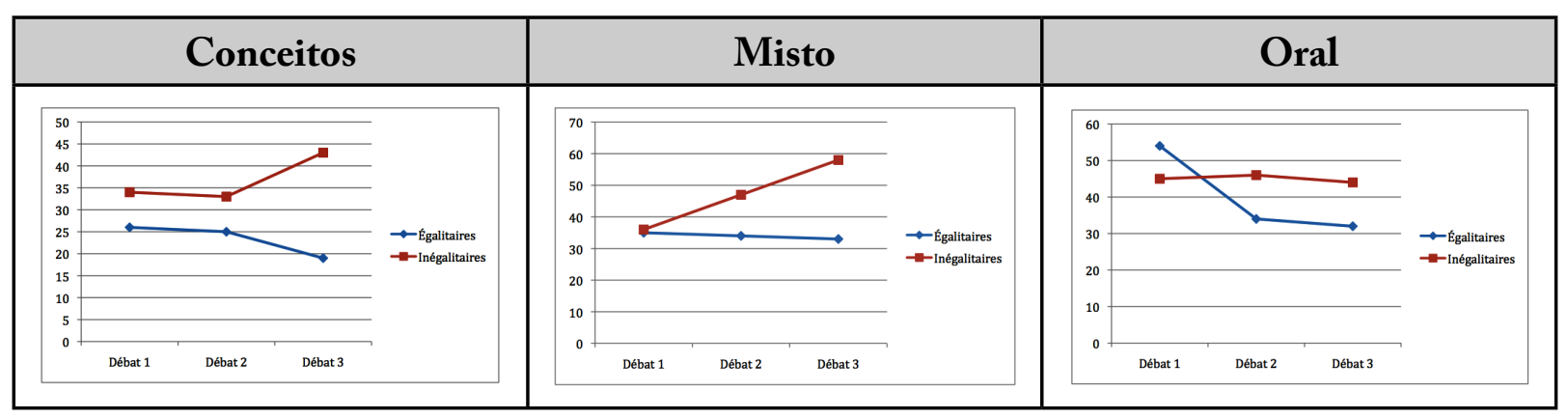


Finalmente, nós observamos que a distribuição da fala não ocorre da mesma maneira nas três modalidades. Essas diferenças certamente são causadas pela maneira como o moderador e as moderadoras gerem o debate. As duas moderadoras formadas para o oral (modalidades oral e mista) deixam a palavra circular livremente entre os(as) diferentes participantes, o que permite trocas diretas entre elas e eles. Notemos que apenas a moderadora da modalidade oral não parecia ter compreendido seu papel desde a primeira produção, em razão do número restrito de intervenções. Contudo, na modalidade conceitos, o moderador, não sendo formado ao oral, faz mais e mais esforço para impedir que os(as) intervenientes tomem o turno sem sua autorização. Durante o fim do debate intermediário, estas observações aparecem muitas vezes: "PSIU você, OK PARE ESPERE, PSIU, PSIU". $\mathrm{Na}$ produção final, elas se intensificam: "ACABOU O TEMPO ACABOU O TEMPO ACABOU O TEMPO calma ok silêncio". Somente a moderadora formada de maneira intensiva (a cada semana) sobre o oral toma consciência de seu papel para reequilibrar as tomadas de turno e distribuí-las às pessoas mais discretas, evitando de distribuí-las de modo mecânico, ou seja, em uma ordem pré-definida. Essa sensibilidade pode ser identificada no fim do debate intermediário, quando ela diz: "dou a palavra à senhora Lala porque ela não falou muito". Essa maneira de gerir o debate se mostrou, sem dúvida, eficaz, contribuindo para uma melhor distribuição da fala entre os(as) participantes.

\section{À guisa de conclusão}

O dispositivo Atelier Filé dá pistas concretas para fazer evoluir as capacidades argumentativas no oral dos alunos no contexto da prática reiterada do debate regrado, buscando, ao mesmo tempo, um procedimento de educação cidadã. Dar aos alunos o poder de falar contribui para desvendar as relações de dominação em jogo na sociedade? Um ensino semanal sobre o oral, sobre o (sistema de) gênero ou os dois vai ter efeito sobre as distribuições desiguais da fala?

\footnotetext{
8 Nota das tradutoras: em francês, "CHUT toi, OK STOP ATTENDEZ, CHUT, CHUT ».

9 Nota das tradutoras: em francês, "TEMPS MORT TEMPS MORT TEMPS MORT calme ok silence ».
}

COPPOLA, A., DOLZ, J. Ensinar o debate regrado sobre as (des)igualdades entre os sexos no primário: Evolução da distribuição da fala entre os(as) participantes 
Segundo nossos primeiros resultados sobre a distribuição do turno, que não são generalizáveis, a prática reiterada do debate durante um período de cinco semanas, pela implementação do Atelier Filé, permite um desenvolvimento dos turnos de fala entre os jovens alunos e uma melhor distribuição da fala nas modalidades em que o oral foi estudado (modalidades oral e mista). Na modalidade conceitos, os turnos de fala se desenvolvem em estrela a partir das intervenções do moderador, não formado sobre as funções que caracterizam seu papel, o que impede as trocas diretas entre os debatedores e as debatedoras.

Uma análise mais fina mostra, aliás, que oferecer intervenções ligadas às discriminações (modalidades conceitos e mista) permite aos alunos, interpretando papeis fictícios desigualitários, melhor integrar e teatralizar seu papel em relação à posição desigualitária a defender. De fato, nesses grupos, os(as) alunos(as) que desempenham papéis desigualitários monopolizam cada vez mais os turnos de fala, desenvolvendo estratégias, tais como tomar à força (a palavra) ou comunicar mais entre si. Além disso, a posição desigualitária permanece dominante da produção inicial à produção final no conjunto das produções, o que coloca em evidência uma facilidade maior para encarnar esse papel, o que não é surpreendente em uma sociedade predominantemente heterossexista. Salientamos, a esse respeito, que os(as) alunos(as) estão interpretando um papel fictício e que elas e eles mostram uma tomada de consciência nos retornos metacognitivos após os debates regrados, durante o Focus Group, no fim da sequência, sobre o caráter sexista de suas intervenções, apesar da facilidade e da influência das intervenções desigualitárias no jogo.

Enfim, a experiência mostra a dificuldade de encarar uma distribuição igualitária da fala entre meninas e meninos. Formá-los especificamente para os mecanismos discriminatórios e para o sistema de gênero, no contexto de um debate regrado, não permite ir na direção de uma igualdade das tomadas de turno de fala entre meninos e meninas. Apenas na modalidade conceitos, a evolução mostra progressos interessantes desse ponto de vista. Por fim, torna-se então evidente que essa dimensão no grupo oral e misto mereceria ser levada em consideração na realização do Atelier Filé, o que convida a buscar uma melhor articulação entre um ensino sobre a igualdade e o oral, que não é totalmente bem-sucedido nos três 
Linha D’Água (Online), São Paulo, v. 33, n. 2, p. 19-38, maio-ago. 2020

grupos. Seguir em direção a uma dinâmica de distribuição igualitária da fala continua sendo um desafio.

\section{Referências}

BOURDIEU, P.; PASSERON, J.-C. La reproduction. Éléments d'une théorie du système d'enseignement. Paris : Les éditions de Minuit, 1970.

BRONCKART, J.-P. Activité langagière, textes et discours. Pour un interactionnisme socio-discursif. Paris: Delachaux et Niestlé, 1997.

BROPHY,J.-E., GOOD, T.-L. Teacher behavior and student achievement. IN: WITTROCK, M. C. (Ed). Handbook of Research on Teaching. New York: Macmilan, 1986, p. 328-375.

CHAMBERLAND, L. L'Impact de l'bomophobie sur la persévérance et la réussite scolaire, rapport de recherche, Fonds de recherche pour la société et la culture, Québec, 2010.

COLLET, I. Comprendre l'éducation au prisme du genre. Carnets des sciences de l'éducation, Université de Genève, 2017.

COLLET, I.; DAYER, C. (Eds.). Former envers et contre le genre (Raisons éducatives) Bruxelles: De Boeck, 2014.

COLLET, I.; MOSCONI, N. Les infor-maticiennes: de la dominance de classe aux discriminations de sexe? Nouvelles questions féministes, v. 19, n. 2, p. 100-103, 2010.

COLOGNESI, S.; DESCHEPPER, C. Itinéraires comme dispositif d'enseignement/apprentissage de l'oral? Quand les élèves du primaire apprennent à réaliser des reportages audiovisuels. IN: LAFONTAINE, L.; DUPONT, P. (Eds.). Collectif du REF 2017. Toulouse: Presses Universitaires du Midi, 2019.

COLOGNESI, S.; DOLZ, J. Un dispositif de formation des enseignants : construire des scénarios pour développer les capacités orales des élèves du primaire. IN: DE PIETRO, J-F.; FISHER, C.; GAGNON, R. (Eds.). L'oral aujourd'hui : perspectives didactiques. Recherches en Didactique du Français, 9. Namur : Presses universitaires de Namur, 2017, p. 177-199.

COPPOLA, A., DOLZ, J. Ensinar o debate regrado sobre as (des)igualdades entre os sexos no primário: Evolução da distribuição da fala entre os(as) participantes 
Linha D'Água (Online), São Paulo, v. 33, n. 2, p. 19-38, maio-ago. 2020

COPPOLA, A., COLOGNESI, S.; COLLET, I. (submetido). Enseigner le débat régulé sur les (in)égalité entre les sexes et les sexualités. L'effet de l'Atelier Filé sur l'adhésion des élèves au système de genre au primaire. Revue GEF (3)

DAYER, C. Sous les pavés, le genre : hacker le sexisme. La Tour-d'Aigue: Éditions de l'Aube, 2017.

DOLZ, J., NOVERRAZ, M.; SCHNEUWLY, S. S’exprimer en français. Séquences didactiques pour l'oral et pour l'écrit. Bruxelles: De Boeck, 2001.

DOLZ, J.; SCHNEUWLY, B. Pour un enseignement de l'oral. Initiation aux genres formels à l'école. Paris : ESF, [1998] 2006.

DUPONT, P. Lépistémologie du concept de genre et ses conséquences praxéologiques en didactiques de l'oral. Repères, 54, p. 141-166, 2016.

FREIRE, P. Pédagogie des opprimés. Suivi de Conscientisation et Révolution. Paris: Petite collection Maspero, 1974.

GARCIA-DEBANC, C. Enseigner l'oral ou enseigner des oraux? Le français aujourd'bui, v. 195, p. 107-118, 2016.

JARLEGAN, A.; TAZOUTI, Y.; FLIELLER, A. L'hétérogénéité sexuée en classe: effets de genre sur les attentes des enseignant(e)s et les interactions verbales enseignant(e)s-élève. Les Dossiers des sciences de l'éducation, v. 26, p. 33-50, 2011.

MARRO, C. Dépendance-indépendance à l'égard du genre. Recherche et formation, v. 69, p. 6580, 2012.

MOSCONI, N. Comment les pratiques enseignantes fabriquent-elles de l'inégalité entre les sexes? Les Dossiers des Sciences de l'Éducation, v. 5, p. 97-109, 2001.

MOSCONI, N. Genre et éducation des filles. Des clartés de tout. Paris: L'Harmattan, 2017.

PATIN, B. Le jeu de rôles: pratique de formation pour un public d'adultes. Les Cabiers Internationaux de Psychologie Sociale, v. 67-68, p. 163-178, 2005.

ROWE, M. Micro-affirmations and Micro-inequities. Journal of the International Ombudsman Association, v. 1, n. 1, p. 45-48, 2008.

COPPOLA, A., DOLZ, J. Ensinar o debate regrado sobre as (des)igualdades entre os sexos no primário: Evolução da distribuição da fala entre os(as) participantes 
Linha D’Água (Online), São Paulo, v. 33, n. 2, p. 19-38, maio-ago. 2020

SENECHAL, K. Expérimentation et validation de séquences didactiques produites selon une ingénierie didactique collaborative. L'enseignement de la discussion et de l'exposé critique au secondaire (thèse de doctorat inédite), Université Laval, Québec, Canada, 2016.

VOUILLOT, F. Lorientation aux prises avec le genre. Travail, genre et sociétés, v. 2, n. 18, p. 87$108,2007$.

Recebido: 22/07/2020.

Aprovado: 25/07/2020.

COPPOLA, A., DOLZ, J. Ensinar o debate regrado sobre as (des)igualdades entre os sexos no primário: Evolução da distribuição da fala entre os(as) participantes 